\title{
DESIGN AND ANALYSIS OF DRIVE SHAFT FOR HEAVY DUTY TRUCK
}

\author{
P.Parveen Sulthana ${ }^{1}$, K.Aruna ${ }^{2}$, T.Krishna Rao ${ }^{3}$, H.G.Shivakumar ${ }^{4}$ \\ ${ }^{I}$ M.Tech Scholar, Department of Mechanical Engineering, SV University College of Engineering, Tirupati, \\ Andhra Pradesh, India \\ ${ }^{2}$ Assistant Professor, Department of Mechanical Engineering, SV University College of Engineering, Tirupati, \\ Andhra Pradesh, India \\ ${ }^{3}$ Professor and Director of School of Mechanical Engineering, REVA UNIVERSITY, Bangalore, Karnataka, India \\ ${ }^{4}$ Department of Mechanical Engineering, Bangalore, Karnataka, India \\ parisulthana.16@gmail.com,aruna_svu@yahoo.com,krishnaraot@rediffmail.com,hgshiva@gmail.com
}

\begin{abstract}
Drive shafts in commercial heavy duty vehicle are subjected to cyclic loads due to variation in the torque demanded by the varying road loads. Cases of failure of the drive shaft of heavy duty trucks have been reported, which provides an opportunity to investigate the issue.

In this project an attempt has been made on prediction of fatigue life of the drive shaft using FEA technique. The load spectrum acting on the drive shaft is calculated for specified terrain. Structural analysis was carried out on the FE model of drive shaft, and potential areas of high stress concentration are obtained. Von Mises stress, fatigue damage, fatigue life, factor of safety and total deformation are the results of fatigue analysis.

It was observed that from the static analysis that the roots of the splines are the areas of high stress concentration. The fatigue analysis revels that the drive shaft fails in the region of high stress concentration as expected. The fatigue life of the component is found to be infinite for design pay load. The life of the drive shaft for 40\% and 50\% over load is 69806 kilometers and 20564 kilometers respectively. The present work can be used in automobile industry as a reference for predicting life of any component, in the drive line of the automobile subjected to non constant amplitude loading.
\end{abstract}

Keywords: Fatigue, Cumulative Damage, Stress-life, Duty cycle, Numerical Fatigue Analysis, Palmgren-Miner Linear damage rule, Rain-flow cycle counting.

\section{INTRODUCTION}

The focus of this project is to predict the fatigue life of drive shaft of a heavy duty truck that fails during the service period. Fatigue, one out of many, is the cause of failure. Fatigue life of the drive shaft is predicted for the design load and for other cases of 10, 20, 3040 and 50 percent overload are also calculated.

\section{PROBLEM STATEMENT}

Predicting the fatigue life of Drive Shaft of a heavy duty truck from a duty cycle calculated for two kilometers.

Several cases of drive shaft failure of TATA 1613 truck have been reported in the service station during a span of 2years. Figure 1 shows the failed drive shaft of the truck and Table 1. shows date and kilometers, the vehicle had done when cases were reported. Visual examination of the component reveals the presence of symptoms, "beach marks" or "striations", of fatigue failure. Of all the components inspected some failed due to over load which can be made out from the brittle fracture of the shaft.
Kilometre reading and date on which failure have been reported

\begin{tabular}{|l|l|l|l|}
\hline $\begin{array}{l}\text { S } \\
\text { No }\end{array}$ & $\begin{array}{l}\text { Kilometer } \\
\text { Reading }\end{array}$ & $\begin{array}{l}\text { Complaint } \\
\text { Date }\end{array}$ & Sale Date \\
\hline 1 & 30,384 & $6 / 5 / 2007$ & $4 / 04 / 2006$ \\
\hline 2 & 75006 & $9 / 6 / 2007$ & $29 / 05 / 2006$ \\
\hline 3 & 10010 & $16 / 05 / 2007$ & $24 / 02 / 2007$ \\
\hline 4 & 44843 & $29 / 05 / 2007$ & $20 / 03 / 2006$ \\
\hline 5 & 44001 & $27 / 09 / 2006$ & $22 / 12 / 2005$ \\
\hline 6 & 9012 & $19 / 12 / 2006$ & $11 / 8 / 2006$ \\
\hline
\end{tabular}

\section{OBJECTIVES}

The objectives of the project are

- To review the literature on fatigue analysis and to set a stage for problem formulation

- To study relevant analytical models for fatigue of automotive drive shafts that are available in the literature

- To create geometric and FE model of the drive shaft for fatigue analysis

- To perform static analysis and to identify the stress concentration area of the drive shaft 
- To predict the fatigue life of the drive shaft subjected to various load from the road load data

\section{METHODOLOGY}

Methodology adapted to achieve the objectives

- Literature review for fatigue failure analysis is carried out by referring journals, books, manuals, technical papers and related documents

- Relevant analytical model for fatigue analysis are studied

- The geometric model of the drive shaft of is created by using CATIA

- Duty cycle is calculated from road topology

- Stress analysis of the drive shaft is carried out using ANSYS Workbench

- Fatigue analysis of the drive shaft is carried out using ANSYS Workbench

- Fatigue life of the drive shaft is predicted using ANSYS Workbench

\section{SOFTWARES USED}

- CATIA

- ANSYS Workbench

Technical specifications of the vehicle

\begin{tabular}{|c|c|}
\hline \multicolumn{2}{|l|}{ ENGINE } \\
\hline Model & $697 \mathrm{NA}$ \\
\hline Type & $\begin{array}{l}\text { Water cooled, direct } \\
\text { injection diesel engine }\end{array}$ \\
\hline No. of Cylinders & 6 inline \\
\hline Bore / Stroke & $97 \mathrm{~mm} \times 128 \mathrm{~mm}$ \\
\hline Capacity & $5675 \mathrm{cc}$ \\
\hline $\begin{array}{l}\text { Max. Engine Output (as } \\
\text { per DIN 70020) }\end{array}$ & $130 \mathrm{PS}$ at $2800 \mathrm{rpm}$ \\
\hline Max torque & $\begin{array}{l}\text { 37mkg.(363 Nm)at } 1800- \\
\text { 2000rpm }\end{array}$ \\
\hline \multicolumn{2}{|l|}{ GEAR BOX } \\
\hline Model & TATA GBS-40 \\
\hline Type & $\begin{array}{l}\text { Synchromesh on all forward } \\
\text { gears }\end{array}$ \\
\hline No. of Gears & 5 forward and one reverse \\
\hline \multirow[t]{6}{*}{ Gear ratios } & $1 \mathrm{st}-8.98$ \\
\hline & 2nd -3.99 \\
\hline & $3 \mathrm{rd}-2.50$ \\
\hline & 4 th -1.51 \\
\hline & 5 th -1.00 \\
\hline & Reverse - 6.93 \\
\hline Ratio(final drive ratio) & $41 / 6$ \\
\hline
\end{tabular}

\section{Mesh details.}

\begin{tabular}{|l|l|}
\hline Element Type / Shape & Solid 45 / Tetrahedrons \\
\hline Elements Size & $5 . e-003 \mathrm{~m}$ \\
\hline No. of Elements & 33158 \\
\hline No. of Nodes & 57743 \\
\hline
\end{tabular}

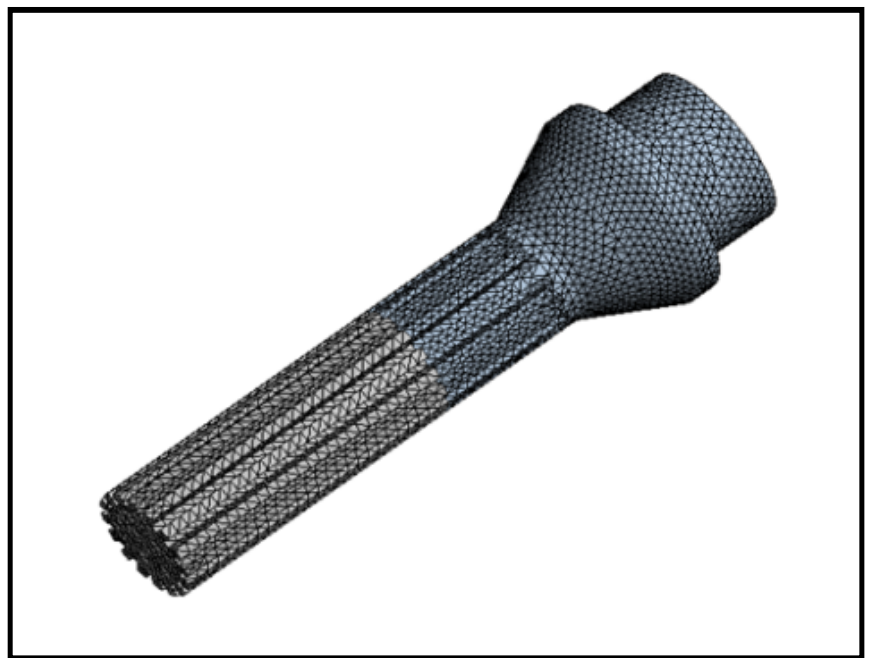

Finite Element model of drive shaft

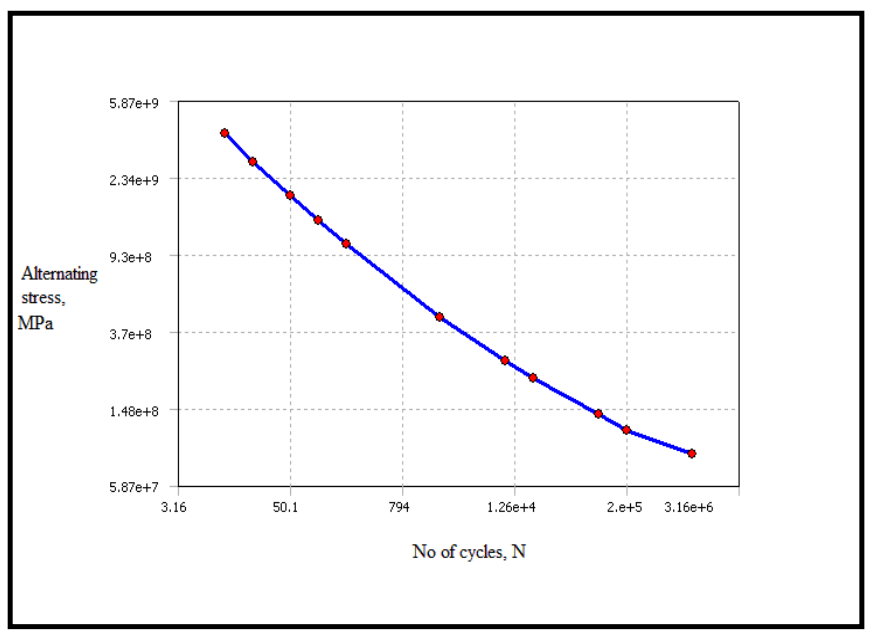

S-N curve of structural steel

Material properties of structural steel.

\begin{tabular}{|c|c|}
\hline \multicolumn{2}{|l|}{ Structural Properties } \\
\hline Material & Structural Steel \\
\hline Volume & $5.9968 \mathrm{e}-004 \mathrm{~m}^{3}$ \\
\hline Mass & $4.7075 \mathrm{~kg}$ \\
\hline Young's Modulus & $2 . \mathrm{e}+011 \mathrm{~Pa}$ \\
\hline Poisson's Ratio & 0.3 \\
\hline Density & $7850 . \mathrm{kg} / \mathrm{m}^{3}$ \\
\hline Thermal Expansion & $1.2 \mathrm{e}-0051 /{ }^{\circ} \mathrm{C}$ \\
\hline Tensile Yield Strength & $2.5 \mathrm{e}+008 \mathrm{~Pa}$ \\
\hline Compressive Yield Strength & $2.5 \mathrm{e}+008 \mathrm{~Pa}$ \\
\hline Tensile Ultimate Strength & $4.6 \mathrm{e}+008 \mathrm{~Pa}$ \\
\hline
\end{tabular}

\section{Calculation of duty cycle}

The longitudinal section of a road profile measuring 2 kilometres, between Gaddankerri and Semekerri, location of which is shown in the Figure 15 is obtained [14] for the calculation of duty cycle. The velocity of the truck is calculated by equating rolling resistance, air resistance and gradient resistance of the road selected to the rated power of engine with a transmission efficiency of 0.98 . 


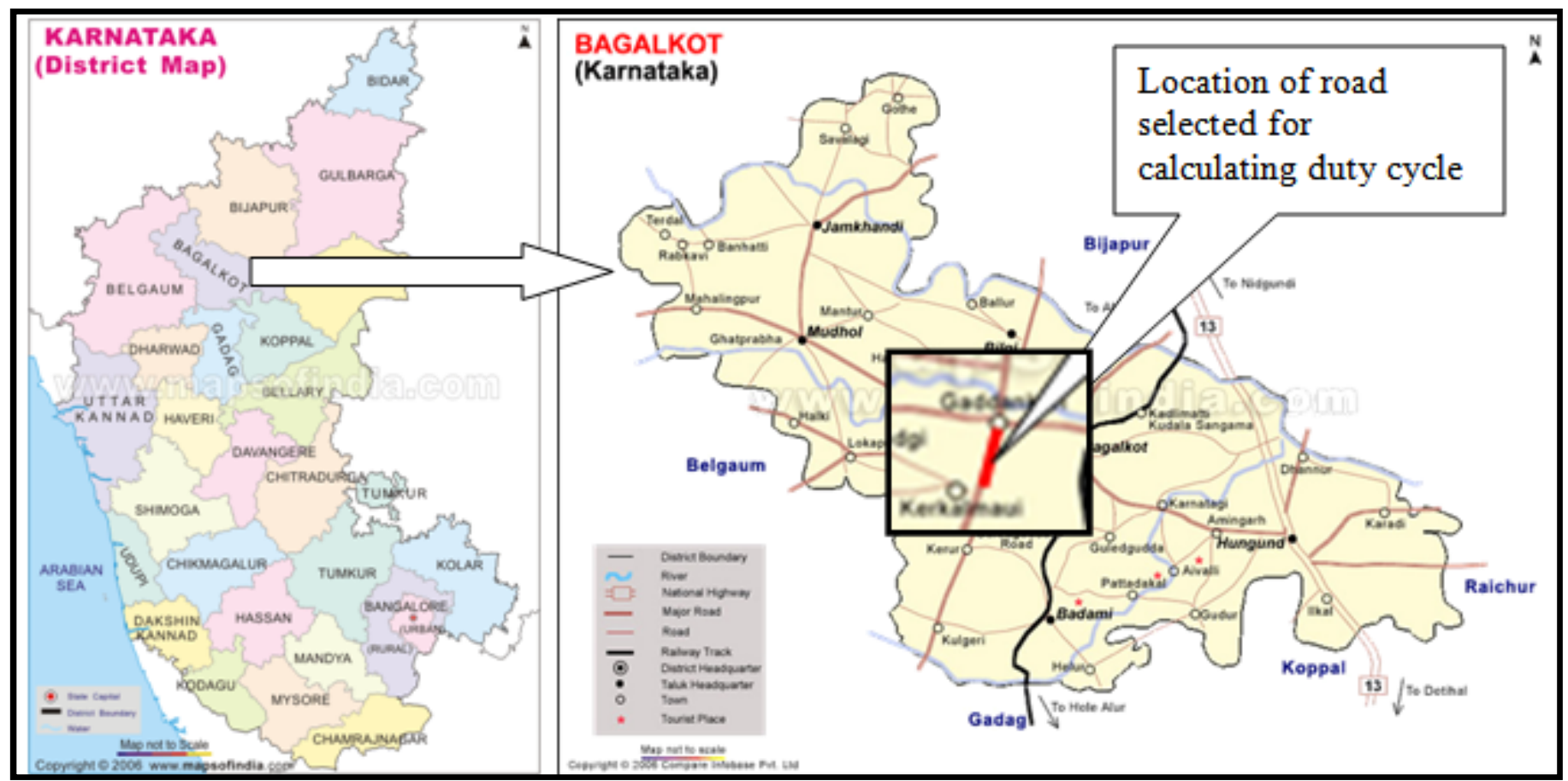

Figure 1: Location of road selected for calculating duty cycle.

Figure 15 shows the elevation (longitudinal section) of road with horizontal distance from a reference point. Details of longitudinal section of road are added at the end of the report.

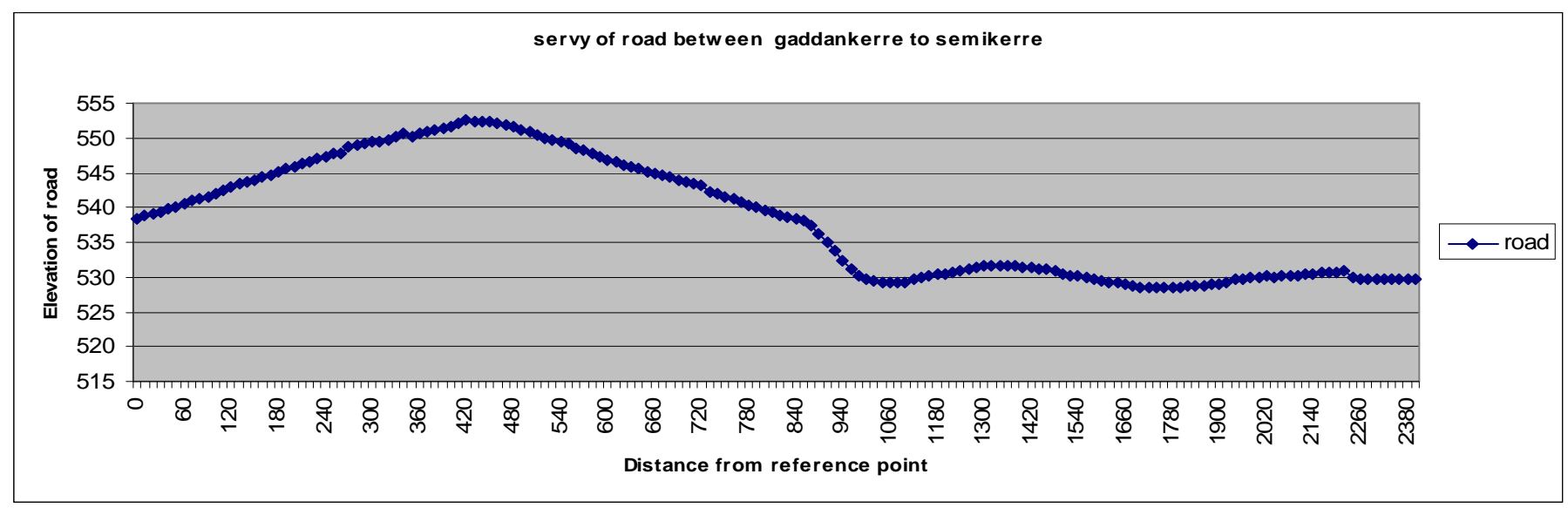

Figure 2: Longitudinal section of the road

\section{Following are the assumption made during calculations}

The frontal projected area of the truck is $4 \mathrm{~m}^{2}$

- The rolling resistance is constant

- The positive gradient (i.e. when the truck is ascending a hill) is added to the total resistance and negative gradient (i.e. when the truck is descending a hill) is subtracted from the total resistance

- The truck is always supplying rated power all the time i.e. maximum power of the engine.

- A representative value of 0.015 is used for the constant of rolling resistance.

- A value of 0.045 is used for the co-efficient of air resistance for trucks.

- Transmission efficiency is $0.98 \%$
- When full power of engine is supplied to the vehicle down the slope, the velocity of the vehicle exceeds its maximum (78 kmph) as calculated. During such cases the vehicle velocity is assumed to be $60 \mathrm{kmph}$.

\section{Calculations of vehicle velocity}

The calculation of vehicle velocity, sited is for first span of 10 meters starting from the reference point, with a vertical gradient of 0.335 meter. On the same guidelines velocity is calculated for whole road.

Power $=$ Velocity $\times$ total resistance

total resistance $=R_{\mathrm{a}}+R_{g}+R_{r}$ 
Rolling resistance, $\mathrm{R}_{\mathrm{r}}=(\mathrm{a}+\mathrm{Vb}) \mathrm{W}$

$$
\begin{aligned}
& =(0.015+0.00016 \mathrm{~V}) 16200 \times 9.81 \\
& =\frac{2354.4 \times 1000}{3600}+\frac{25.1136 \mathrm{~V} \times 1000}{3600} \\
& =662.175+7.0632 \mathrm{~V}
\end{aligned}
$$

The value of $\mathrm{a}=0.015 \mathrm{a}$ representative value and $\mathrm{b}=$ 0.00016 are considered [13]

$$
\begin{array}{r}
\text { Air resistance, } R_{a}=K_{a} A V^{2} \\
=0.045 \times 4 \times V^{2} \\
=2.32 \times V^{2}
\end{array}
$$

$K_{a}=0.045$ is used for trucks and lorries.

Gradient resistance, $\mathrm{R}_{\mathrm{g}}=\mathrm{m} \times \mathrm{g} \times \sin \theta$

$$
\begin{aligned}
& =16200 \times 9.81 \times 0.93 \\
& =149336.9608 \mathrm{~N}
\end{aligned}
$$$$
95=V \times\left(149336.96+2.32 V^{2}+662.175+7.0632 V\right)
$$

The roots for the cubic equation are solved in hand calculation in MS Excel. The imaginary roots are neglected and integer values are taken into consideration. Hence, for the above equation the roots are $-8.62+52.43 i,-8.62-52.43 i$, 14.12. Similarly, the roots for all the equations are solved. Appendix shows values of all the roots for design and overload cases. Once the value of vehicle velocity is calculated, the linear velocity of vehicle is co-related to wheel speed using the relation

$$
\begin{aligned}
& V=r \omega \\
& \text { where, } \omega=\frac{2 \times \pi \times N}{60}
\end{aligned}
$$

From the above equation the speed with which the axle shaft is calculated

$$
N=\frac{V \times 60}{2 \times \pi \times r}=\frac{14.4611 \times 60}{2 \times \pi \times 0.55}=251.05 \text { r.p.m. }
$$

Since, it is assumed that the transmission efficiency of the driveline is 0.98 , out of $95 \mathrm{Kw}$ power available at the engine, $93 \mathrm{Kw}$ is transmitted through drive shaft. Hence, torque transmitted by drive shaft is calculated by the relation

$$
T=\frac{P \times 60}{2 \times \pi \times N}=\frac{93000 \times 60}{2 \times 3.142 \times 251.05}=520.16 N-m
$$

\section{Details of boundary conditions}

There are 16 teeth on the drive shaft milling. By visual inspection it is evident that there is uniform wear on all teeth. Hence, the torque is transmitted by all the teeth. The calculated torque is applied on all the teeth, i.e. along side of teeth face. Since, the drive shaft tube is fastened to the milling all degrees of freedom are constrained on this face. Figure 16 shows the boundary conditions applied on the FE model.

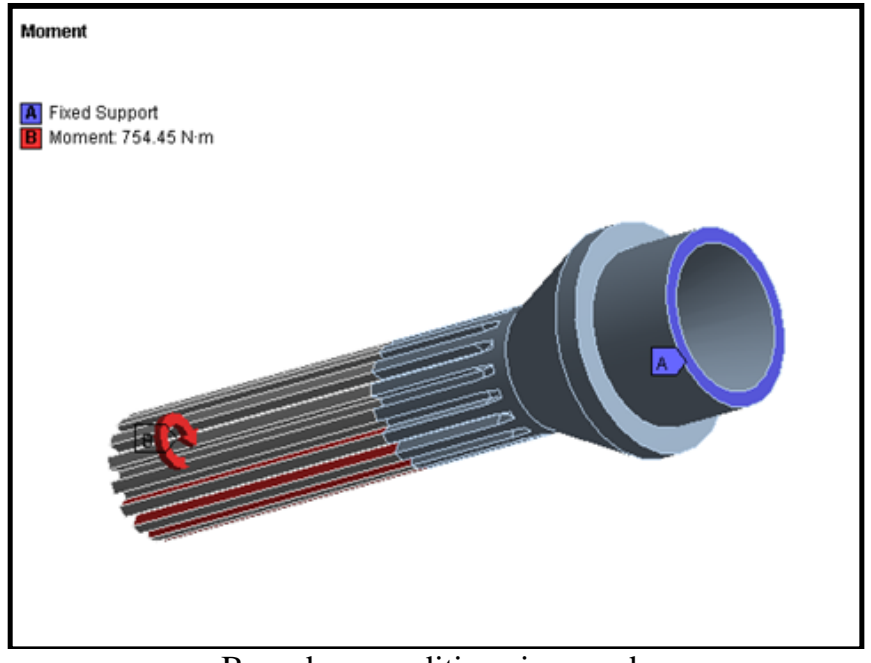

Boundary conditions imposed

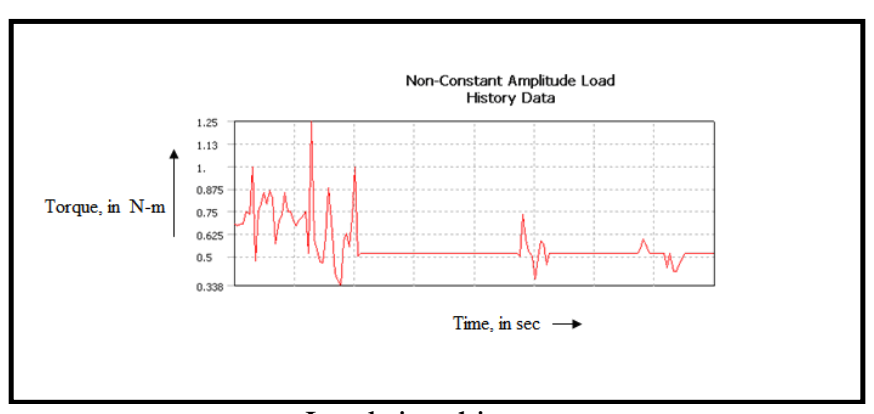

Load-time history

\section{RESULT}

The following results are discussed

- Fatigue life

- Fatigue damage at a specified design life

- Fatigue factor of safety at a specified design life

- Rain flow matrix output

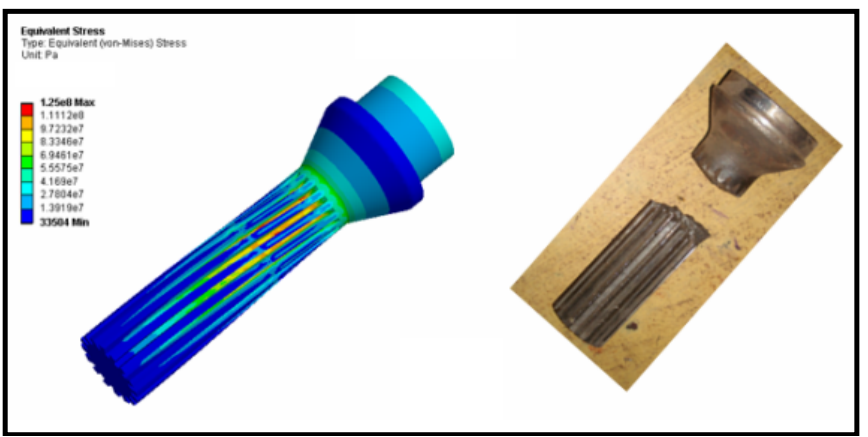



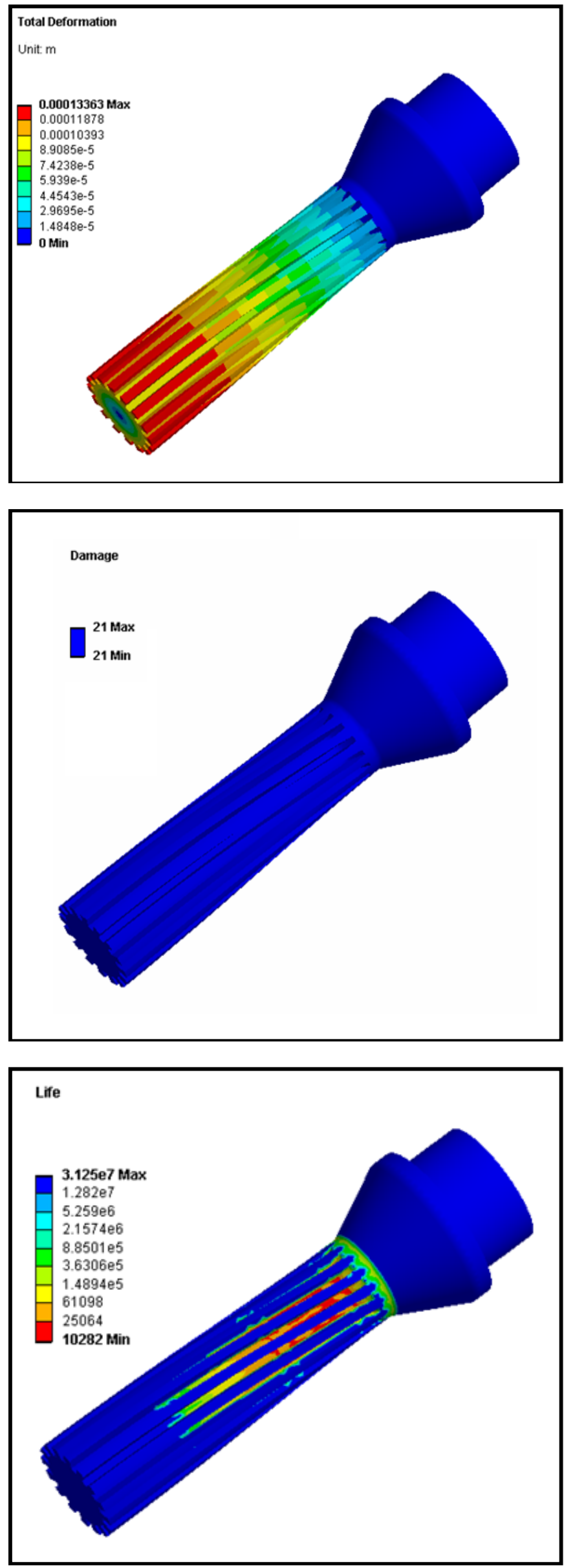

\section{CONCLUSION}

The present work has resulted in various conclusions and also introduced scope for future work. The various conclusions that can be drawn from the project are listed below.

- Accurate representation of dimensions of the component/s under analysis by adopting the reverse engineering technique like co-ordinate measuring machine or laser scanner

- Minimizing discretization error by remeshing of fillets

- Realistic representation of the load time history experienced by the component

- Static stress analysis reveals that the roots of the splines of the drive shaft are the area of maximum stress concentration. The maximum stress experienced by the drive shaft for the specified terrain and for the design load is $125 \mathrm{MPa}$

- The total deformation of the drive shaft is $0.13 \mathrm{~mm}$

- The factor of safety for the drive shaft is more than 1 . Hence, the drive shaft is safe.

- For design load, life of the drive shaft is infinite For 10, 20 and $30 \%$ overloading the life of drive shaft is infinite. For $40 \%$ overloading the life of drive shaft is finite and 69806 kilometers. For 50\% overloading the life of drive shaft is finite and 20564 kilometers

- The life of the drive shaft is different for different duty cycle.

- Over all the cause for fatigue failure of the drive shaft is due to overloading.

\section{REFERENCES}

[1] F. S. Silva, (2003) "Analysis of a vehicle crankshaft failure" Engineering Failure Analysis, International Journal of Fatigue, 21-26-28, 2003.

[2] Kawamura A., Nakajimima and Yokota M., (1998), "Prediction for truck endurance from the basis of Road Profile Measurements", SAE, 982788.

[3] Steinwender G., Gaier B., (1998), "Improving the Life Time of Dynamically Loaded Components by Fatigue Simulation", SAE, 982220.

[4] Bonnen and Topper, (2002), "The Effect of Bending Over Loads on Torsional Fatigue in Normalized 1045 Steel', International Journal of Fatigue, 21-23-23, 2002.

[5] Stephens Ralph, Fatemi Ali, stephens Robert R., Fuchs Henry, (2001), "Metal Fatigue in Engineering", John Willey, First Edition 2001.

[6] Priya B M, (2006), "Fatigue Failure Analysis of Rear Axle Shaft of a Heavy Commercial Vehicle", Project Report, MSRSAS, Bangalore, September-2006.

[7] Chandra shekar, (2006), "Fatigue Failure Analysis of Crankshaft of a Car", Project Report, MSRSAS, Bangalore, September-2006.

[8] V. Prakash and K. Apramwyan, (1998) "An FEM Based Approach to Crankshaft Dynamics and Life Estimation", SAE, 982560.

[9] S. Farfan , C. Rubio-Gonzalez, T. CervantesHernandez, and G. Mesmacque, (2004), "High cycle 
fatigue, low cycle fatigue and failure modesof a carburized steel", International Journal of Fatigue, 26 (2004) 673-678.

[10] Shinichi Chiba, Kimihiko Aoyama and Kenji Yanabu, (1998), "Fatigue Strength Prediction of Truck Cab by CAE" SAE, 982065.

[11] Joseph Edward Shigley, Charles R. Mischke, (1989) "Mechanical Engineering Design", McGraw-Hill Book Company, Fifth International Edition, 1989.

[12] N W M Bishop, F Sherratt, (2000), "Finite Element Based Fatigue Calculations", NAFEMS, September 2000.

[13] Dr N. K. Gere, (2004), "Automobile Technology", Khanna Publishers, first edition, 2004

[14] Vijay Kumar Meti, Vijay Patil, Ejaz Kalburgi and Umes Ghatge, (2004), "A Project Report on Highway" BasavehwaraEngineeringCollege, Department of Civil Engineering, Bagalkot, 2004. 